\title{
Biodiversidade de bactérias antagônicas a fungos associados à sindrome da morte do capim-marandu (Brachiaria brizantha)
}

\author{
Maira Laís Both BOURSCHEIDT ${ }^{1}$, Kellen Banhos do CARMO $^{2}$, Bruno Carneiro PEDREIRA ${ }^{3}$, \\ Gilcele de Campos Martin BERBER ${ }^{1}$, Anderson Ferreira ${ }^{4 *}$ \\ ${ }^{1}$ Universidade do Estado de Mato Grosso, Sinop, MT, Brasil. \\ ${ }_{2}^{2}$ Palm Beach State College, Palm Beach Gardens, Florida 33410, USA. \\ ${ }^{3}$ Kansas State University, Southeast Research and Extension Center, Parsons 67357, USA. \\ ${ }^{3}$ Embrapa Agrossilvipastoril, Sinop, MT, Brasil. \\ *E-mail: anderson.ferreira@embrapa.br \\ (ORCID: 0000-0003-3477-8729; 0000-0002-5373-680X; 0000-0003-4663-954X; 0000-0001-9840-9768; 0000-0003-3176-089X)
}

Recebido em 05/02/2021; Aceito em 11/10/2021; Publicado em 18/12/2021.

\begin{abstract}
RESUMO: A síndrome da morte do capim-marandu (Brachiaria brizantha) é um dos principais problemas na degradação das pastagens no bioma Amazônia. A morte das forrageiras ocorre durante a época chuvosa por suscetibilidade a fitopatógenos. Assim, objetivou-se estudar sistemas de produção e selecionar bactérias antagônicas a Fusarium spp., um dos agentes fitopatogênicos. Os isolados bacterianos foram obtidos de 10 sistemas de produção, mata nativa e pousio, na chuva e na seca. Realizou-se a caracterização molecular de isolados por sequenciamento. Dois isolados de Fusarium foram testados. Para o patógeno 1, na época da chuva, $7,5 \%$ dos isolados apresentaram antagonismo enquanto na seca foi $15 \%$. Para o patógeno 2 , nem todos os isolados positivos para o patógeno 1 foram eficientes no controle, demonstrando a ocorrência de interações entre isolados bacterianos e Fusarium spp. Na chuva, para o patógeno 1, a mata apresentou maior número de isolados positivos $(20 \%)$. Na seca, os tratamentos mata, 1-Floresta e 8-integração lavoura floresta para o patógeno 1, foram os que apresentaram maior número de positivos $(25 \%)$. Na identificação molecular, 8 foram os gêneros bacterianos encontrados: Burkholderia, Bacillus, Brevibacillus, Streptomyces, Pseudomonas, Escherichia, Paenibacillus e Pandoraea, em que a maioria é descrita como capaz de controlar Fusarium spp. in vitro.
\end{abstract}

Palavras-chave: Burkholderia; controle biológico; integração lavoura-pecuária-floresta.

\section{Biodiversity of bacteria antagonic to fungi associated with syndrome's death palisadegrass (Brachiaria brizantha)}

\begin{abstract}
The death syndrome of marandu grass (Brachiaria brizantha) is one of the main problems in the degradation of pastures in the Amazon biome. Plant death occurs during the rainy season due to susceptibility to phytopathogens. Thus, the objective was to study production systems and select bacteria antagonistic to Fusarium spp., one of the phytopathogenic agents. Bacterial isolates were obtained from 10 production systems, native forest and fallow, in rain and drought season. Molecular characterization of isolates was carried out by sequencing. Two Fusarium isolates were assessed. For pathogen 1, in the rainy season, 7.5\% of the isolates showed antagonism, while in the dry season it was $15 \%$. For pathogen 2 , not all isolates positive for pathogen 1 were efficient in the control, showing correlations between bacterial isolates and Fusarium spp. In the rain, for pathogen 1 , the forest showed the highest number of positive isolates $(20 \%)$. In the dry season, the treatments forest, 1-Forest and 8-plant-forest integration for pathogen 1, were ones with the highest number of positives $(25 \%)$. In the molecular identification, 8 bacterial genera were found: Burkholderia, Bacillus, Brevibacillus, Streptomyces, Pseudomonas, Escherichia, Paenibacillus and Pandoraea, most of which are described as able to controlling Fusarium spp. in vitro.
\end{abstract}

Keywords: Burkholderia; biological control; integrated crop-livestock-forest.

\section{INTRODUÇÃO}

O rebanho bovino brasileiro possui grande expressividade na economia nacional e a pecuária de corte é uma das atividades mais importantes do agronegócio brasileiro. Essa atividade representa cerca de $8.5 \%$ do Produto Interno Bruto com um rebanho bovino de 213 milhões de cabeças (ABIEC, 2019). O sistema de produção animal em pastagens é muito explorado para a produção de carne, e tem grande potencial para atender a demanda futura, a qual precisa ser mais eficiente e sustentável, com preços competitivos, qualidade do produto, e foco no bem-estar animal nos princípios sociais. Nesse sentido, é necessário buscar a intensificação da produção em pastagens, buscando o melhor manejo das pastagens e melhor utilização de áreas já abertas, porém ainda com potencial de produção aquém do ideal (PEDREIRA et al. 2018). Nesse cenário, os sistemas de Integração Lavoura-Pecuária-Floresta (ILPF) vem se apresentando como uma ferramenta de intensificação da produção com diversificação, o qual permite a produção de grãos, carne, leite e madeira em uma mesma área, visando a 
lucratividade e a conjunta preservação ambiental (FARIAS NETO, 2019).

A conversão de sistemas convencionais para sistemas de integração impacta positivamente nas propriedades física, química e microbiológica do solo e no ciclo dos nutrientes devido ao aumento da matéria orgânica do solo, contribuindo para maior produtividade do sistema (RUSSELL et al., 2006). Por outro lado, síndrome da morte do capim-marandu tem sido apontada como um dos principais problemas na região Amazônia e responsável pela degradação das pastagens (PEDREIRA et al. 2019).

Essa síndrome se manifesta durante a estação chuvosa, e seus sintomas se apresentam na forma de amarelecimento, murchamento e morte de touceiras da gramínea em áreas delimitadas da pastagem (reboleiras) (ANDRADE; VALENTIM 2007). O problema é desencadeado pela umidade excessiva do solo, seguida pelo ataque de fungos nas raízes do capim-braquiarão, associado à reconhecida baixa tolerância desse capim ao alagamento do solo. Assim, a baixa adaptação do capim-braquiarão ao encharcamento do solo agiria como fator de predisposição para a instalação da síndrome, a qual seria resultante de respostas bioquímicas e fisiológicas da planta e das características biológicas, físicas e químicas do solo sob excesso de água (DIAS-FILHO 2006).

Essa cultivar não está adaptada a estas condições, ficando suscetível ao ataque de fungos de solo dos gêneros Rhiroctonia, Pythium (DUARTE et al. 2007) e Fusarium (DIAS; TOLETO, 1993). No estado do Mato Grosso, existem 108.185 produtores rurais com atividades ligadas à bovinocultura, e a área afetada com tal problema é de 2,23 milhões de hectares, representando 8,6\% da área de pastagem total do estado (IMEA, 2011, EMBRAPA, 2014). Isso significa que o aumento de áreas acometidas pela SMB pode causar um impacto negativo muito grande na produção pecuária brasileira, diminuindo o lucro e causando sérios prejuízos econômicos tanto para o produtor rural, quanto para o país (PEDREIRA et al. 2019).

Presentes nos mais diversos ambientes, os microrganismos podem ser benéficos ou maléficos, provocando eventualmente doenças nos animais e plantas (MOREIRA E SIQUEIRA, 2006). O solo, ambiente do presente estudo, é um recurso natural vivo e dinâmico que pode promover a sustentabilidade biológica e sanidade das plantas. Os microrganismos presentes no solo podem apresentar potencial antagônico entre si e, portanto, potencial no controle biológico de outros microrganismos, inclusive fitopatógenos (MOREIRA E SIQUEIRA, 2006).

Nesse contexto, os objetivos desse trabalho foram: i) identificar isolados bacterianos antagônicos a fungos do gênero Fusarium spp., associados a morte do capim-marandu (Brachiaria brizantha); ii) identificar se sistemas integrados de produção, naturalmente, apresentam maior número de bactérias antagônicas a fungos do gênero Fusarium spp., no solo.

\section{MATERIAL E MÉTODOS}

\section{1. Área experimental}

As amostras de solo para o estudo de diversidade microbiana foram coletadas em um experimento composto por modelos de sistemas agrícolas de produção, em Sinop, Mato Grosso, na área experimental da Embrapa

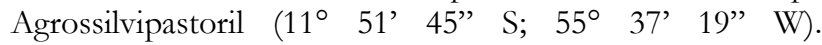
Adicionalmente, foram avaliados um pousio e uma área de mata nativa. O município situa-se no bioma Amazônia. Dos
12 locais em que as amostras foram coletadas, 10 são oriundas de modelos de sistemas agrícolas integrados (ILPF), em uma área de cerca de 72 hectares, com parcelas experimentais compreenderam $200 \times 100 \mathrm{~m}$, em blocos casualizados com 4 repetições. Os modelos de produção exclusivos e integrados foram: 1-F: floresta; 2-L: lavoura; 3P: pecuária; 4-IPL: integração pecuária-lavoura; 5-ILP: integração lavoura-pecuária; 6-ILF: integração lavourafloresta; 7-IPF: integração pecuária-floresta; 8- ILPF: lavoura e floresta por 2 anos e após pecuária e floresta por 2 anos; 9 ILPF: pecuária e floresta por 2 anos e lavoura e floresta por 2 anos; 10- ILPF: integração lavoura pecuária floresta. Além disso, uma amostra foi coletada em mata nativa e outra em área de pousio, ambas em áreas adjacentes aos 10 modelos.

\subsection{Coleta de solo}

A amostragem foi realizada em duas épocas: janeirofevereiro (chuva) e setembro-outubro (seca). O experimento estava com um ano após o plantio. O solo foi coletado na profundidade de $0-10 \mathrm{~cm}$, com auxílio de um trado holandês. Amostragens simples, de 20 a 25 sub-amostras, formaram uma amostra composta. Posteriormente, o solo foi acondicionado em embalagem apropriada, transportado até o laboratório de Microbiologia de Solos da Embrapa Agrossilvipastoril, onde o solo permaneceu em câmara fria a cerca de $4^{\circ}$ C. Para coleta, em cada parcela foi realizada a limpeza do material utilizado, a fim de evitar contaminação cruzada.

\subsection{Isolamento e seleção de bactérias antagonistas}

Para seleção de microrganismos usados no antagonismo foi necessário a realização de plaqueamento com amostras de solo, para isolamento de colônia bacterianas, a seleção das bactérias, sua purificação e por fim a armazenagem.

Para isolamento dos microrganismos, as amostras de solo foram pesadas (1 grama) e diluídas em $9 \mathrm{~mL}$ de tampão fosfato (PBS, contendo $\left[\mathrm{g} \mathrm{L}^{-1}\right]$ 1,44 Na $\mathrm{NPO}_{4} ; 0,24 \mathrm{KH}_{2} \mathrm{PO}_{4}$; $0,20 \mathrm{KCl} ; 8,00 \mathrm{NaCl} ; \mathrm{pH} 7,4)$ esterilizado e incubadas sob agitação (150 r.p.m.) por uma 1 h. Posteriormente, diluições $\left(10^{-3}, 10^{-4}, 10^{-5}\right)$ foram semeadas sobre meio de cultura TSA 10\% (Triptona Soja Agar). As culturas ficaram incubadas em câmara $\mathrm{BOD}$ a $28^{\circ} \mathrm{C}$ até o crescimento.

Para cada tratamento foram selecionadas 20 bactérias utilizadas no ensaio de antagonismo, o que totalizou 240 isolados bacterianos testados. As amostras de solo foram enumeradas de 1 ao 48 (10 sistemas, mata e pousio, com 4 repetições). Posteriormente fez-se a purificação dos isolados por meio da técnica de esgotamento, em placa de Petri com meio de cultivo TSA $10 \%$ (Triptona Soja Agar). Caracterizou-se as colônias por descrição evidenciando a coloração, consistência, reflexão à luz e formato. Após a identificação dos isolados bacterianos esses foram devidamente identificados e armazenados em solução de glicerol $20 \%$ a $-80^{\circ} \mathrm{C}$, para uso nos testes posteriores. Doze bactérias de cada repetição foram usadas no teste, considerando as mais divergentes em coloração, consistência, reflexão à luz e formato.

As avaliações de antagonismo foram realizadas utilizando o método de cultura pareada (MARIANO, 1993), que consiste no confronto direto do antagonista (bactérias selecionadas dos diferentes tratamentos) e do fitopatógeno (fungo Fusarium spp.). O teste foi realizado em placas de Petri com meio BDA (batata-dextrose-ágar) incubadas de 9 a 13 dias em câmera $\mathrm{BOD}$ a $28^{\circ} \mathrm{C}$. O resultado foi positivo na 
formação de halo de inibição e/ou quando o fungo não ultrapassou a bactéria. As análises foram realizadas em duplicata.

Dois isolados de Fusarium spp foram testados contra as bactérias selecionadas: um oriundo de uma planta de soja acometida (patógeno 1) e outro de solo onde ocorreu a morte da forrageira (patógeno 2). Ambos patógenos foram cedidos pelo laboratório de fitopatologia da Universidade Federal de Mato Grosso, Sinop. Somente os isolados bacterianos antagônicos ao patógeno 1 foram testados contra o patógeno 2.

\subsection{Caracterização molecular dos isolados bacterianos}

Apenas bactérias antagônicas ao fungo foram caracterizadas molecularmente. A amplificação dos genes $16 \mathrm{~S}$ rDNA foi realizada por PCR (reação em cadeia da polimerase) direto de colônias sem extração de DNA. A quantidade de $1 \mu \mathrm{L}$ dessa suspensão bacteriana foi utilizada como fonte de DNA para realização da PCR. Os iniciadores ou primers utilizados foram o PO27F (5' GAGAGTTTGATCCTGGCTCAG - 3' e 1387R (5' CGGTGTGTACAAGGCCCGGGAACG - 3’). A qualidade das amostras foi verificada por eletroforese em gel de agarose a $1 \%$.

Para a identificação, os produtos de PCR de bactérias foram purificados com etanol $70 \%$ e parcialmente sequenciados utilizando o iniciador "reverse". As amostras foram sequenciadas no Centro de Pesquisa sobre o genoma humano e células-tronco - USP, visualizadas no programa Chromas versão 2.1.1 (2012) e comparadas por BLAST (Basic Local Alignment Search Tool) (ALTSCHUL et al., 1990).

\section{RESULTADOS}

Para o patógeno 1, na época da chuva, houve $7,5 \%$ de antagonismo, considerando o total de isolados avaliados, enquanto na seca esse valor foi maior (15\%). Para o patógeno 2 , na época da chuva, 2,5\% foi o total de antagonismo, valor menor do que no outro período avaliado $(6,25 \%)$. Apenas na época da seca, para o patógeno 1, todos os tratamentos apresentaram pelo menos uma bactéria antagonista.

Quando considerados os tratamentos, para o patógeno 1, a mata apresentou maior número de isolados positivos $(20 \%)$ na época da chuva, e para a época da seca, os tratamentos mata, 1-F e 8-ILPF apresentaram maior número de isolados antagônicos (25\%) (Figura 1).

Para o patógeno 2, na época da chuva, o melhor resultado antagonista foi em 6-ILF $(10 \%)$, e para a outra época analisada, o tratamento 8-ILPF (20\%) foi mais representativo na avaliação (Figura 2).

Entre os isolados antagônicos ao patógeno 1, mas não todos necessariamente ao patógeno 2, 30 bactérias foram selecionadas, por características morfocromáticas após PCR de colônia, e foram sequenciadas (Tabela 1). O gênero mais encontrado nas amostras analisadas foi Burkholderia, seguido por Bacillus, Brevibacillus e Streptomyces, além de outros de menor número (Pseudomonas, Escherichia, Paenibacillus e Pandoraea), embora não possam ser considerados menos importantes. Salienta-se que 3 bactérias não foram identificadas, onde o resultado apresentado por BLAST é de bactéria não cultivada.

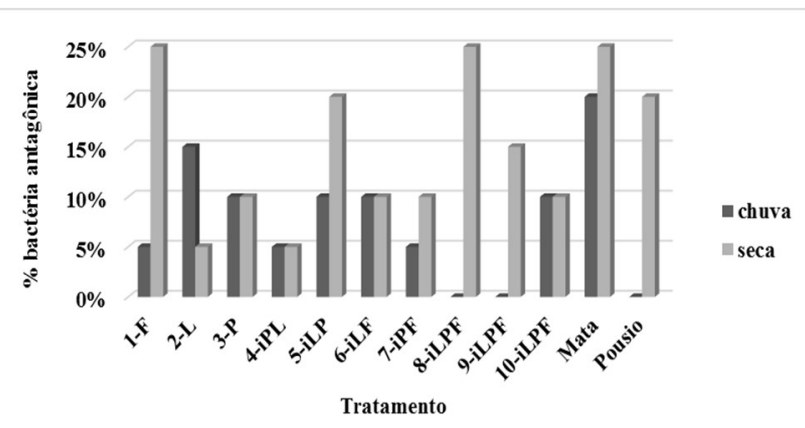

Figura 1. Antagonismo positivo de bactérias isoladas de solo sob diferentes cultivos contra Fusarium spp. isolado de soja (patógeno 1). 1-F: floresta; 2-L: lavoura; 3-P: pecuária; 4-iPL: integração pecuárialavoura; 5-ILP: integração lavoura-pecuária; 6-ILF: integração lavoura-floresta; 7-iPF: integração pecuária-floresta; 8-ILPF: lavoura e floresta por 2 anos e após pecuária e floresta por 2 anos; 9ILPF: pecuária e floresta por 2 anos e lavoura e floresta por 2 anos; 10-ILPF: integração lavoura pecuária floresta.

Figure 1. Positive antagonism of bacteria isolated from soil under different crops against Fusarium spp. soybean isolate (pathogen 1). 1F: forest; 2-L: tillage; 3-P: livestock; 4-iPL: livestock-crop integration; 5-ILP: crop-livestock integration; 6-ILF: crop-forest integration; 7-iPF: livestock-forest integration; 8-ILPF: crop and forest for 2 years and after livestock and forest for 2 years; 9ILPF: livestock and forest for 2 years and crop and forest for 2 years; 10 ILPF: livestock farming integration with the forest.

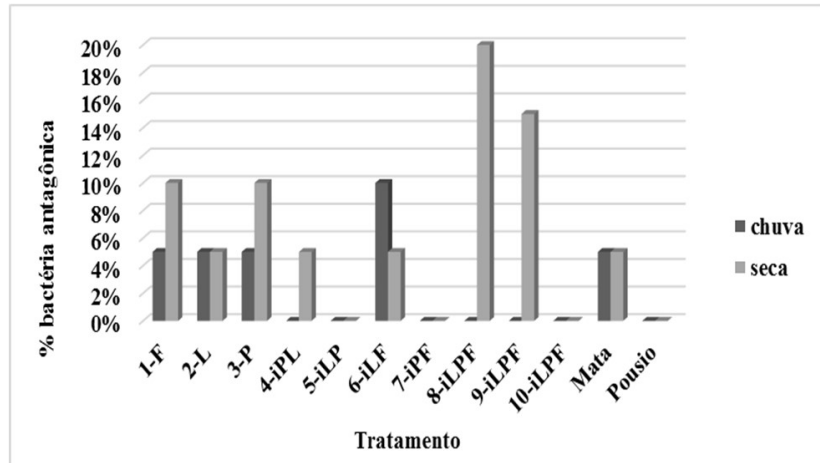

Figura 2. Antagonismo positivo de bactérias retiradas de solo sob diferentes cultivos contra Fusarium spp. isoladas de solo onde ocorreu morte de capim Marandu (patógeno 2). 1-F: floresta; 2-L: lavoura; 3-P: pecuária; 4-iPL: integração pecuária-lavoura; 5-ILP: integração lavoura-pecuária; 6-ILF: integração lavoura-floresta; 7 IPF: integração pecuária-floresta; 8-ILPF: lavoura e floresta por 2 anos e após pecuária e floresta por 2 anos; 9ILPF: pecuária e floresta por 2 anos e lavoura e floresta por 2 anos; 10-ILPF: integração lavoura pecuária floresta.

Figure 2. Positive antagonism of bacteria from soil under different crops against Fusarium spp. isolated from soil where death of Marandu grass (pathogen 2) occurred. 1-F: forest; 2-L: tillage; 3-P: livestock; 4-iPL: livestock-crop integration; 5-ILP: crop-livestock integration; 6-ILF: crop-forest integration; 7-IPF: livestock-forest integration; 8-ILPF: crop and forest for 2 years and after livestock and forest for 2 years; 9ILPF: livestock and forest for 2 years and crop and forest for 2 years; 10-ILPF: livestock farming integration with the forest.

\section{DISCUSSÃO}

Quando consideramos antagonismo dos gêneros de bactérias obtidos no presente trabalho é possível citar alguns exemplos descritos na literatura como: Burkholderia antagônica à Fusarium spp., patógeno de gramíneas (LUVIZOTTO, 2008; BARRERA-GALICIA et al. 2021); Bacillus spp. capaz de controlar através de antagonismo, 
fungos fitopatogênicos de pós-colheita de frutos, incluindo Fusarium oxysporum 120512 (ANGONESE et al. 2009); Bacillus subitilis, controlando o crescimento de fungos fitopatogênicos, dentre eles Fusarium moniliforme (FIGUEIREDO et al. 2010); Bacillus sp. e Brevibacillus brevis antagônicos a Fusarium oxysporum f. ciceris sp. (PÉREZ et al., 2009); Paenibacillus macerans, reduzindo significativamente patógenos em sementes de trigo, entre eles Fusarium graminearum (CÓRIO DA LUZ, 2003). Adicionalmente, Pseudomonas, Bacillus agaradhaerens, Escherichia coli e Streptomyces também tem sido relatados na literatura como controladores de Fusarium (MELO E VALARINI, 1995; SHIOMI et al. 2008; ROCHA; MOURA, 2013). Já para o gênero Pandoraea, na literatura consultada, não se encontrou antagonismo ao Fusarium spp.

Tabela 1. Identificação de bactérias antagônicas a Fusarium spp. Table 1. Identification of bacteria antagonistic to Fusarium spp.

\begin{tabular}{|c|c|c|c|c|c|}
\hline Tratamento & Isolado & Gênero & Espécie (Blast-NCBI) & $\% *$ & Linhagem de Referência \\
\hline $1 \mathrm{~F}$ & 25.2 & Burkholderia & B. cepacia & 99 & KJ634149.1 \\
\hline $1 \mathrm{~F}$ & 25.5 & Paenibacillus & P. peoriae & 85 & NR_117739.1 \\
\hline $1 \mathrm{~F}$ & 32.7 & Brevibacillus & B. brevis & 89 & JX490070.1 \\
\hline $1 \mathrm{~F}$ & 25.9 & Uncultured bacterium & - & 84 & KF841905.1 \\
\hline $2 \mathrm{~L}$ & 26.11 & Streptomyces & S. sporoverrucosus & 97 & KC508633.1 \\
\hline $3 \mathrm{P}$ & 2.1 & Pseudomonas & sp. & 84 & KJ729599.1 \\
\hline $3 \mathrm{P}$ & 11.12 & Burkbolderia & B. cepacia & 95 & KJ634149.1 \\
\hline $4 \mathrm{IPL}$ & 29.5 & Burkholderia & sp. & 98 & KJ672507.1 \\
\hline 5 ILP & 34.1 & Brevibacillus & B. brevis & 98 & KJ735916.1 \\
\hline 5 ILP & 34.11 & Burkbolderia & B. cepacia & 94 & KJ634149.1 \\
\hline 5 ILP & 34.12 & Bacillus & sp. & 85 & KF228923.1 \\
\hline $6 \mathrm{ILF}$ & 14.8 & Paenibacillus & P. polymyxa & 98 & EU741059.1 \\
\hline $6 \mathrm{ILF}$ & 22.1 & Bacillus & B. subtilis & 99 & KJ736013.1 \\
\hline $6 \mathrm{ILF}$ & 39.5 & Uncultured bacterium & - & 77 & KF088528.1 \\
\hline $8 \mathrm{ILPF}$ & 7.10 & Streptomyces & S. abikoensis & 98 & KC954556.1 \\
\hline $8 \mathrm{ILPF}$ & 16.9 & Uncultured bacterium & - & 90 & KF109649.1 \\
\hline $8 \mathrm{ILPF}$ & 16.7 & Bacillus & B. subtilis & 97 & KJ736013.1 \\
\hline 9 ILPF & 38.9 & Burkbolderia & sp. & 99 & KJ672506.1 \\
\hline 10 ILPF & 8.4 & Burkbolderia & sp. & 91 & KC987404.1 \\
\hline $10 \mathrm{ILPF}$ & 21.5 & Streptomyces & S. phaeopurpureus & 90 & KC466283.1 \\
\hline 10 ILPF & 37.7 & Brevibacillus & B.agri & 84 & FJ715821.1 \\
\hline pousio & 41.3 & Burkebolderia & B. cenocepacia & 98 & FJ232612.1 \\
\hline pousio & 42.7 & Burkbolderia & B. cepacia & 99 & JF927933.1 \\
\hline pousio & 42.2 & Burkbolderia & B. cepacia & 96 & FJ232612.1 \\
\hline mata & 47.10 & Bacillus & B. subtilis & 99 & KJ736013.1 \\
\hline mata & 46.12 & Burkbolderia & sp. & 98 & GU479034.1 \\
\hline mata & 47.1 & Burkebolderia & sp. & 93 & AF247494.1 \\
\hline mata & 45.5 & Pandoraea & P. thiooxydans & 79 & NR_116008.1 \\
\hline mata & 46.7 & Burkholderia & sp. & 99 & GU479034.1 \\
\hline mata & 45.6 & Escherichia & E.coli & 92 & JX267124.1 \\
\hline
\end{tabular}

1-F: floresta; 2-L: lavoura; 3-P: pecuária; 4-IPL: integração pecuária-lavoura; 5-iLP: integração lavoura-pecuária; 6-iLF: integração lavoura-floresta; 8-ILPF: lavoura e floresta por 2 anos e após pecuária e floresta por 2 anos; 9ILPF: pecuária e floresta por 2 anos e lavoura e floresta por 2 anos; 10-ILPF: integração lavoura pecuária floresta. *Similaridade.

Bactérias do gênero Burkholderia apresentam capacidade de fixação biológica de nitrogênio (OLIVEIRA, 2007), fato também evidenciado para Pseudomonas (REZENDO, 2007); Bacillus spp. e Burkholderia se apresentam como promotores de crescimento em plantas (GUERREIRO, 2008; MOREIRA, 2013; HWANG et al., 2021), o que complementa a importância antagônica a fitopatógenos, como demonstrado com este trabalho. A época da seca teve mais bactérias antagonistas, e para ambos patógenos, os tratamentos com maior intensificação do uso da terra como 8-ILPF apresentaram melhores resultados. O que demonstra possível capacidade de encontrar um controlador biológico à Fusarium spp. nestes sistemas integrados, que assim como a mata mantém um ambiente mais equilibrado e com menores variações e distúrbios no solo ao longo do ano. A conversão de sistemas convencionais para sistemas de integração pode influenciar positivamente nas propriedades física, química e microbiológica do solo e no ciclo dos nutrientes devido ao aumento da matéria orgânica do solo, contribuindo para maior produtividade do sistema (RUSSELL et al., 2006).

Diferentes sistemas de manejo, sistema intensivo de lavoura, pastagem permanente, pastagem com rotação de culturas e pastagem recém estabelecidas influenciaram a estrutura e atividade e funcionalidade das comunidades microbianas do solo (PLASSART et al., 2008). Isso indica que o uso de sistemas integrados de produção que envolvam uma maior complexidade de espécies vegetais sendo cultivadas e, maior intensificação sustentável do uso da terra, podem manter um equilíbrio microbiano ao longo do ano de forma que patógenos como Fusarium spp sejam controlados naturalmente no solo. Os microrganismos presentes no solo podem apresentar a capacidade de competir com o patógeno, bem como, ter o crescimento mais efetivo que o patógeno (PATIN et al., 2016).

Nas áreas de floresta nativa e sem interferência antrópica, é natural encontrar maior diversidade funcional quando 
comparadas a áreas agrícolas, ainda que os microrganismos se apresentem em menor abundância. Essas áreas são consideradas sustentáveis pela capacidade de resiliência dos microrganismos ali presentes independente dos fatores abióticos e bióticos (TORSVIK; ØVREÅS, 2002). Corroborando com essa realidade, a porcentagem de isolados com capacidade controlar Fusarium spp encontrados na Mata nativa foi estável e constante independente da estação do ano. Nesse sentido, os resultados obtidos nesse estudo sugerem que o uso de sistemas integrados de produção, com cultivos de múltiplas espécies num mesmo local, podem ser uma estratégia para aumentar naturalmente o número de bactérias antagônicas aos fungos do gênero Fusarium spp. associados a morte do capim-marandu (Brachiaria brizantha). Esse estímulo pode manter as populações desses patógenos em uma quantidade suprimida sendo uma forma de evitar ocorrência de doenças e a síndrome da morte do capimmarandu. Além desse estímulo natural os sistemas integrados de produção se mostraram um ótimo "hot spot" para prospecção de bactérias antagônicas para estudos em novos biosinsumos para uso agropecuário no bioma Amazônia.

\section{CONCLUSÕES}

Em todos os modelos de produção agrícola, na mata nativa e na área de pousio foi possível encontrar e identificar isolados bacterianos antagônicos a fungos do gênero Fusarium spp. associados a morte do capim-marandu (Brachiaria brizantha). Indicando que há populações naturalmente ocorrendo no solo e que as práticas culturais e de manejo podem favorecer naturalmente a manutenção das mesmas; O maior número de bactérias antagônicas a fungos do gênero Fusarium spp. está fortemente ligado com a estação seca do ano e, em menor intensidade com os sistemas de produção. O gênero bacteriano mais encontrado nas amostras analisadas foi Burkholderia, seguido por Bacillus, Brevibacillus e Streptomyces.

\section{AGRADECIMENTOS}

Ao Conselho Nacional de Desenvolvimento Científico e Tecnológico (CNPq), pela bolsa fornecida e pelo apoio financeiro no projeto número 476013/2012-7. A Embrapa Agrossilvipastoril pelo apoio financeiro e de estrutura física.

\section{REFERÊNCIAS}

ABIEC_Associação Brasileira das Indústrais Exportadoras de Carne. Perfil da Pecuária no Brasil 2019. Brasília: ABIEC, 2019. 49p. Disponível em: http://abiec.com.br/publicacoes/beef-report-2019/

ALTSCHUL, S. F.; GISH, W.; MILLER, W.; MYERS, E. W.; LIPMAN, D. J. Basic local alignment search tool. Journal of Molecular Biology, London, v. 215, p. 403-410, 1990.

ANDRADE, C. M.; VALENTIM, J. F. Síndrome da morte do capim-brizantão no Acre: características, causas e soluções tecnológicas. Rio Branco: Embrapa Acre, 2007. 41p. (Documentos, 105). Disponível em: https://ainfo.cnptia.embrapa.br/digital/bitstream/CPA F-AC-2010/16734/1/capimbrinzantao-no-acre.pdf

ANGONESE, M. T.; DELLA GIUSTINA JÚNIOR, L. H. P.; PANSERA, M. R.; PAGNO, R. S.; MEZZOMO, F.; ZORZI, E.; PEREIRA, C. O. F.; RIBEIRO, RUTE, T. DA S. Efeito fungistático de Bacillus spp. sobre fungos fitopatogênicos. Revista Brasileira de Agroecologia, Dois Vizinhos, v. 4 n. 2 p. 97-100, 2009.
BARRERA-GALICIA, G. C.; PENICHE-PAVÍA, H. A.; PEÑA-CABRIALES, J. J.; COVARRUBIAS, S. A.; VERA-NÚÑEZ, S. A.; DÉLANO-FRIER, J. P. Metabolic footprints of Burkholderia sensu lato Rhizosphere bacteria active against maize fusarium pathogens. Microrganisms, v. 9, n. 10, p. 1-20, 2021. DOI: https://doi.org/10.3390/microorganisms9102061

CÓRIO DA LUZ, W. Avaliação dos tratamentos biológico e químico na redução de patógenos em semente de trigo. Fitopatologia Brasileira, Brasília, v. 28, n. 1, p. 93-95, 2003. DOI: https://doi.org/10.1590/S010041582003000100014

DIAS, D. C. F. S.; TOLEDO, F. F. de. Germinação e incidência de fungos em testes com sementes de Brachiaria brizantha Stapf. Scientia Agricola, Piracicaba, v. 50 , n. 1 , p. 68-76, 1993. DOI: https://doi.org/10.1590/S0103-90161993000100011

DIAS-FILHO; M. B. Opções forrageiras para áreas sujeitas ao encharcamento ou alagamento temporário. Belém: Embrapa Amazônia Oriental, 2006. 34p. (Documentos, 239). Disponível em: https://ainfo.cnptia.embrapa.br/digital/bitstream/item /18921/1/Doc-239.pdf

DUARTE, M. L. R.; ALBUQUERQUE, F. C.; SANHUEZA, R. M. V.; VERZIGNASSI, J. R.; KONDO, N. Etiologia da podridão do coleto de Brachiaria brizantha em pastagens da Amazônia. Fitopatologia Brasileira, Brasília, v. 32, n. 3, p. 261-265, 2007.

Embrapa_Empresa Brasileira de Pesquisa Agropecuária. Pesquisas apontam formas de evitar síndrome da morte da braquiária em Mato Grosso. Disponível em: https://www.embrapa.br/busca-de-noticias//noticia/2125574/pesquisas-apontam-formas-de-evitarsindrome-da-morte-da-braquiaria-em-mato-grosso. Acesso em: 24 jun 2021

FARIAS NETO, A. L. de; NASCIMENTO, A. F. do; ROSSONI, A. L.; MAGALHÃES, C. A. de S.; ITUASSU, D. R.; HOOGERHEIDE, E. S. S.; IKEDA, F. S.; FERNANDES JUNIOR, F.; FARIA, G. R.; ISERNHAGEN, I.; VENDRUSCULO, L. G.; MORALES, M. M.; CARNEVALLI, R. A. (Orgs.) Embrapa Agrossilvipastoril Primeiras contribuições para o desenvolvimento de uma Agropecuária Sustentável. Brasília: Embrapa Agrossilvipastoril, 2019. $825 \mathrm{p}$.

FIGUEIREDO, J. E. F.; TEIXEIRA, M. A.; LIMA, G. V. C.; BRESSAN, W.; PINTO, N. F. J.; CASELA, C. R. Atividade antagonista in vitro de Bacillus subtilis contra fungos fitopatogênicos do milho e sorgo. In: Congresso Nacional de Milho e Sorgo, XXVIII. Anais... Goiânia: Associação Brasileira de Milho e Sorgo, 2010. p. 667-673 (Cd-Rom). Disponível em: https://ainfo.cnptia.embrapa.br/digital/bitstream/item /25047/1/0053.pdf

GUERREIRO, R. T. Seleção de Bacillus spp promotores de crescimento de milho. 55f. Dissertação (Mestrado em Agronomia) - Universidade do Oeste Paulista, Presidente Prudente, 2008.

HWANG, H.; CHIEN, P.; HUANG, F.; HUNG, S.; KUO, C.; DENG, W.; CHIANG, E. I.; HUANG, C. A Plant Endophytic Bacterium, Burkholderia seminalis Strain 869T2, Promotes Plant Growth in Arabidopsis, Pak Choi, Chinese Amaranth, Lettuces, and Other 
Vegetables. Microorganisms, v. 9, n. 8, p. 1-18, 2021. DOI: https://doi.org/10.3390/microorganisms9081703

IMEA_Instituto Matogrossense de Economia Agropecuária. Relatório do levantamento sobre a morte de pastagem em MT. Cuiabá: IMEA, 2011, 4p.

LUVIZOTTO, D. M. Caracterização fisiológica e molecular de Burkholderia spp. associadas às raízes de cana-de-açúcar. 94f. Dissertação (Mestrado em Microbiologia Agrícola) - Escola Superior de Agricultura Luiz de Queiroz, Universidade de São Paulo, Piracicaba, 2008.

MARIANO, R. L. R. Métodos de seleção in vitro para o controle microbiológico de patógenos de plantas. Revisão Anual de Patologia de Plantas, v. 1, p. 369409, 1993.

MELO, L S. de; VALARINI, P. J. Potencial de rizobactérias no controle de Fusarium solani (Mart.) Sacc. em pepino (Cucumis sativum L.). Scientia Agricola, Piracicaba, v. 52, n. 2, p. 326-330, $1995 . \quad$ DOI: https://doi.org/10.1590/S0103-90161995000200020

MOREIRA, A. L. de L.; ARAÚJO, F. F. de. Bioprospecção de isolados de Bacillus spp. como potenciais promotores de crescimento de Eucalyptus urograndis. Revista Árvore, Viçosa, v. 37, n. 5, p. 933-943, 2013. DOI: ttps://doi.org/10.1590/S0100-67622013000500016

MOREIRA, F. M. S.; SIQUEIRA, J. O. Microbiologia e Bioquímica do Solo. Lavras: UFLA, 2006. 729p.

OLIVEIRA, M. E. S. de; REZENDE, S.S.; DIDONET, C.C.G.M. Bactérias diazotróficas do gênero Burkholderia: isolamento, diversidade e caracterização em plantas de arroz no cerrado de Goiás. In: Seminário de Iniciação, V. Anais... Anápolis-GO: Científica, 2007.

PATIN, N. V.; DUNCAN, K. R.; DORRESTEIN, P. C.; JENSEN, P. R. Competitive strategies differentiate closely related species of marine actinobacteria. ISME Journal, v. 10, n. 2, p. 478-490, 2016. DOI: $10.1038 /$ ismej.2015.128

PEDREIRA, B. C.; DIAS-FILHO, M. B.; ANDRADE, C. M. S. et al. Convivendo com a síndrome da morte do braquiarão na Amazônia. In: DIAS-FILHO, M. B.; ANDRADE, C. M. S. (Eds) Recuperação de pastagens degradadas na Amazônia. Brasília: Embrapa, 2019, p. p. 127-151.

PEDREIRA, B. C.; DOMICIANO, L. F.; VILELA, L. et al. O estado da arte e estudos de caso em sistemas integrados de produção agropecuária no Centro-Oeste do Brasil. In: DE SOUZA, E. D.; SILVA, F. D. da; ASSMANN, T. S.; et al. (Eds) Sistemas Integrados de Produção Agropecuária no Brasil. 1 ed. Tubarão: Copiart, 2018. P. 277-300

PÉREZ, R. S.; COTA, H. M. C.; GRAVE, M. A. S.; ROMERO, M. V.; DELGADO, J. M. P.; SÁNCHEZ, M. A. A.; FÉLIX, S. V. Antagonismo de isolados de Bacillus sp. hacia Fusarium oxysporum f. sp. ciceris, patógeno del garbanzo. In: Agricultura Sustenible, v6, 1 ed. Anais... Chiapas-México: Universidad Autónoma de Chiapas, 2009.

PLASSART, P.; VINCESLAS, M. A.; GANGNEUX, C.; MERCIER, A.; BARRAY, S.; LAVAL, K. Molecular and functional responses of soil microbial communities under grassland restoration. Agriculture, Ecosystems \& Environment, v. 127, p. 286-293, 2008. DOI: https://doi.org/10.1016/j.agee.2008.04.008
REZENDE, S. S.; OLIVEIRA, M. E. S. de; DIDONET, C. C. G. M. Bactérias diazotróficas do gênero Pseudomonas: isolamento, diversidade e caracterização em plantas de arroz no cerrado de Goiás. In: Seminário de Iniciação, V. Anais... Anápolis-GO: Científica, 2007.

ROCHA, D. J. A.; MOURA, A.B. Controle biológico da murcha do tomateiro causada por Ralstonia solanacearum e Fusarium oxysporum f. sp. lycopersici por rizobactérias. Tropical Plant Pathology, v. 38, n. 5, P. 423-430, 2013. DOI: https://doi.org/10.1590/S198256762013005000025

RUSSELL, A. E.; LAIRD, D. A.; MALlARINO, A. P. Nitrogen fertilization and cropping system impacts on soil quality in Midwestern Mollisols. Soil Science Society of America Journal, v. 70, p. 249-255, 2006. Disponível em: https://core.ac.uk/download/pdf/38936518.pdf

SHIOMI, H. F.; MELO, I. S. de; MINHONI, M. T. de A.Seleção de bactérias endofíticas com ação antagônica a fitopatógenos. Scientia Agrária, Curitiba, v. 9, n. 4, p. 535-538, 2008.

TORSVIK, V.; OVREAS, L. Microbial diversity and function in soil: form genes to ecosystems. Current Opinion in Microbiology, New York, v. 5, p. 240-245, 2002. 